\title{
O ENSINO DE FILOSOFIA A PARTIR DE PROBLEMAS: UMA PROPOSTA PARA A EDUCAÇÃO POPULAR
}

\author{
TEACHING PHILOSOPHY FROM PROBLEMS: \\ A PROPOSAL FOR POPULAR EDUCATION \\ Rafaela Missaggia Vaccari \\ Cainã Link de Lima²
}

\section{RESUMO}

Este artigo visa apresentar a abordagem de um ensino de filosofia pautado majoritariamente em problemas filosóficos, e busca defendê-la como um método eficaz para o uso em sala de aula, especialmente na educação popular. O método conforme endossado por este trabalho consiste na utilização de problemas como mote principal para a elaboração e condução de uma aula de filosofia. No aspecto prático, o artigo se vale da experiência adquirida em dois anos (2018 e 2019) de aulas ministradas no âmbito do Pré-Universitário Popular Alternativa (PUPA), com turmas distintas em cada ano. O Alternativa é um projeto que visa preparar estudantes ao longo de um ano para capacitá-los a realizar o Exame Nacional do Ensino Médio (ENEM). O curso é voltado à população de baixa renda de Santa Maria e região e seu público é majoritariamente composto por alunos(as) formandos do terceiro ano do ensino médio de escolas públicas da cidade. Dado o objetivo do Alternativa, que consiste em revisar os conteúdos centrais do ensino médio no período de menos de um ano, é de vital importância a escolha de um método de ensino que seja dinâmico ao apresentar os conteúdos e hábil em relacioná-los às demais áreas do saber. Desse modo, a melhor metodologia é aquela que se utiliza melhor do tempo disponível de aula para apresentar o essencial a um público com pouca ou nenhuma iniciação no assunto.

Palavras-chave: ensino de filosofia; educação popular; problemas filosóficos; método.

\section{ABSTRACT}

This paper aims to present an approach to teaching philosophy mainly based in philosophical problems and defend it as an effective method for use in the classroom. The method as endorsed by this work consists of using problems as the main guide for creating and conducting a philosophy class especially in popular education. In the practical aspect, this paper is based in two years (2018 and 2019) of classes taught under the Pré-Universitário Popular Alternativa (PUPA), with different classes each year. Alternativa is a project that aims to prepare students over a year to enable them to take the Exame Nacional do Ensino Médio (ENEM). The classes are aimed at the low-income population of Santa Maria and the region and its audience is mostly composed by students graduating from the third year of high school in public schools in the city. As the objective of the Alternativa

1 Graduanda em Filosofia na Universidade Federal de Santa Maria (UFSM) e em Direito na Universidade Franciscana (UFN). Educadora do Pré-Universitário Popular Alternativa (PUPA) de 2018 a 2020. E-mail: rafaelamissaggia@gmail.com 2 Graduado em Filosofia pela Universidade Federal de Santa Maria (UFSM). Educador do Pré-Universitário Popular Alternativa (PUPA) de 2015 a 2019. E-mail: cainalima95@gmail.com 
Thaumazein, Ano IX, v. 13, n. 25, Santa Maria, p. 67-74, 2020.

consists of revising the central contents of school education in a period of less than one year, it is vitally important to choose a teaching method that is dynamic to display the contents and is related to the other areas. Thus, the best methodology is one that uses the best time available to presents the essential to an audience with little or no introduction to the subject.

Keywords: philosophy teaching; popular education; philosophical problems; method.

\section{INTRODUÇÃO}

Questões pedagógicas são - ou, ao menos, deveriam ser - essenciais a todos aqueles que se colocam na posição de educadores de filosofia. Desde sua origem, nota-se uma forte tendência na filosofia em fornecer um lugar central à transmissão de sua mensagem. Isso evidencia-se pela dependência desta para com o diálogo interpessoal, conforme demonstrado à exaustão nos diálogos de Platão pela figura de Sócrates. Nesse sentido, a proposta de partida deste trabalho é mostrar a indissociabilidade da filosofia com questões acerca da metodologia de ensino desta, e, por conseguinte, da necessidade de se ter clareza sobre o público alvo, uma vez que é esse o balizador do ensino.

O objetivo principal deste artigo é apresentar a abordagem de um ensino de filosofia pautado majoritariamente em problemas filosóficos, e busca defendê-la como um método eficaz para o uso em sala de aula, especialmente na educação popular. Do ponto de vista prático, o artigo se vale da experiência adquirida em dois anos (2018 e 2019) de aulas ministradas no âmbito do Pré-Universitário Popular Alternativa (PUPA), com turmas distintas em cada ano. Enquanto um pré-vestibular, o principal objetivo do Alternativa consiste em revisar os principais conteúdos do ensino médio no período de menos de um ano, e, sendo assim, é de vital importância a escolha de um método de ensino que seja dinâmico ao apresentar os conteúdos, e hábil em relacioná-los às demais áreas do saber. Neste contexto, a melhor metodologia é aquela que se utiliza melhor do tempo disponível de aula para apresentar o essencial a um público com pouco ou nenhum conhecimento no assunto.

O texto está estruturado em quatro momentos principais. De início, realizamos um breve diagnóstico do perfil e da composição social dos(as) educandos(as) do projeto Alternativa. O segundo é destinado a explicitar parte da bibliografia brasileira sobre o ensino de filosofia, com foco na sua abordagem a partir de problemas. Para isso, examinamos concisamente Gallo (2012), Cerletti (2009), Obiols (2002), Murcho (2011) e Porta (2014). Em seguida, apresentamos alguns exemplos utilizados em sala de aula. O último, enfim, faz a conexão do que foi proposto com a educação popular de modo mais explícito.

\section{PERFIL E COMPOSIÇÃO SOCIAL DOS(AS) EDUCANDOS(AS) DO PROJETO ALTERNATIVA}

Para fins da discussão, é importante realizar uma breve análise do perfil e da composição social dos educandos do projeto. A pesquisa de Zago (2008) indica que os cursinhos pré-vestibulares populares do Brasil são constituídos por e preocupam-se com grupos sociais tradicionalmente excluídos do ensino superior (negros, moradores de bairros populares, egressos de escolas públicas, pessoas de baixa renda) e, por isso, buscam democratizar o ensino no país auxiliando no acesso desses grupos 
às universidades. Assim, o objetivo central dos cursos populares no Brasil é auxiliar no reparo de um cenário desigual no qual grande parte das vagas nas universidades públicas é ocupada por pessoas de classe média-alta. Em consonância a isso, e adotando um viés freiriano de educação, o Alternativa se consolidou na comunidade santa-mariense.

De modo geral, podemos dizer que existem dois grupos de educandos relativamente bem definidos no projeto: são aqueles que estão concluindo o Ensino Médio em escolas públicas ou que já deixaram de frequentar os bancos escolares há algum tempo. A partir de relatos de experiência oriundos dos próprios educandos, é sabido que, quanto aos que estão concluindo o ensino médio, muitos tiveram aulas de filosofia sendo ministradas por profissionais sem formação específica na área. Geralmente, são professores(as) com graduação em história, geografia ou outras disciplinas que acabam sendo encarregados dessa tarefa. Essa condição ocasiona, naturalmente, uma precarização do ensino. ${ }^{3}$

A respeito dos educandos que finalizaram sua formação escolar (ou que não chegaram a finalizar) há algum tempo, ou seja, que estão retornando aos estudos agora, muitos não estão familiarizados com aulas de filosofia, uma vez que esta disciplina era por diversas vezes negligenciada quando cursaram o Ensino Médio em anos anteriores - vale lembrar que a disciplina de filosofia só tornou-se obrigatória em todas as escolas no ano de 2008.

Essas informações correspondem com a faixa etária dos educandos do projeto: no ano de 2014, por exemplo, 53\% dos educandos tinham até 19 anos (80 alunos); a faixa etária que vai dos 20 aos 29 anos de idade compreendia 46 educandos, ou 31\%; e 16\% dos educandos tinham mais de 30 anos, sendo 24 indivíduos (ALLGAYER; ACOSTA, 2014, p. 3). Os dados são semelhantes em 2018 e 2019, anos nos quais ministramos a disciplina de Filosofia nas turmas 2 e 1, respectivamente.

Ainda em 2014, os educandos apresentaram rendas familiares declaradas compreendidas entre R\$ 358,00 e R\$ 3.033 (Ibid., p. 5). Esses números não sofrem mudanças significativas a cada ano porque há um critério no edital do Processo Seletivo que prevê como renda até o valor de 1,5 salários mínimos quando o candidato mora sozinho ou 1 salário mínimo per capita quando possui família.

Uma outra característica bastante presente e que perceptivelmente tem influência na aprendizagem do educando são as demais atividades que eles realizam durante o dia. Nas turmas em que ministramos as aulas, em 2018 e 2019, a grande maioria também trabalhava, isto é: tinham que conciliar seus estudos à noite no Alternativa conjuntamente com suas atividades laborais diurnas ou, ainda, conciliar as aulas escolares no turno da manhã, o trabalho à tarde e as aulas noturnas do projeto.

Todos estes dados são possíveis a partir das respostas do questionário socioeconômico que todo interessado a disputar uma vaga no Alternativa deve responder, bem como das entrevistas realizadas pelos educadores e educadoras individualmente a cada candidato. Tanto o preenchimento do questionário quanto a entrevista são obrigatórios no processo de seleção do projeto. O conhecimento desses dados é, do mesmo modo, importante visto a necessidade de conhecer o educando com o qual vamos trabalhar e a sua realidade social para estruturar nossos métodos, planos e estratégias pedagógicas de modo adequado.

\footnotetext{
3 É importante destacar que também há educandos no projeto provenientes de instituições que tiveram a disciplina de Filosofia ministrada por professores com formação específica na área. No entanto, o relato do histórico educacional do educando é comumente este.
} 


\section{O ENSINO DE FILOSOFIA A PARTIR DE PROBLEMAS}

Além de conhecer o educando com o qual se está trabalhando, é importante, do mesmo modo, que o educador se mantenha aberto a diferentes propostas metodológicas e busque colocá-las à prova. A inspiração maior para a escrita deste trabalho é a ideia de que discutir sobre bons métodos de ensino é uma tarefa essencial a todo educador. E, claramente, pensar em ensino de filosofia requer pensar em um método de abordagem. Com sorte, temos à nossa disposição uma ótima gama de materiais em língua portuguesa.

A proposta de Silvio Gallo (2012) é uma das mais referenciadas. Em sua obra Metodologia do ensino de filosofia, o professor elenca quatro momentos didáticos que devem contemplar a aula de filosofia. Esses momentos são: sensibilização, problematização, investigação e conceituação.

Na sensibilização o professor procura afetar os alunos com alguma situação, filmes, vídeos, músicas, etc. Na problematização procura-se criar um problema que irá incutir dúvida nos alunos. Essa dúvida precisa ser solucionada. Para isso, há a investigação, que corresponde a recorrer às referências filosóficas para considerar o que já foi dito sobre a situação. Disso, chega-se à conceituação, que consiste na recriação daqueles conceitos que foram apropriados da investigação.

Alejandro Cerletti (2002), caminhando por esse mesmo terreno, também procurou um mapa comum para a aula de filosofia. Ele chegou a uma ideia mais básica e que, acreditamos, também está na essência do modelo proposto por Gallo. À procura de um esquema de didática mínima, Cerletti enuncia dois elementos fundantes da aula: a problematização e a tentativa de resolução (2002, p. 83). Tal modelo básico, que será ligeiramente incrementado por Cerletti nas páginas seguintes do livro, representa, acreditamos, o alicerce da aula de filosofia. É também nesse caminho que Desidério Murcho esboça suas ideias sobre o ensino de filosofia ao sugerir que trabalhemos em aula a partir dos problemas filosóficos, partindo dos mais simples até os mais complexos (2011, p. 15).

Na busca por um modelo geral formal para o ensino de filosofia, Guillermo Obiols (2002) sustenta que um processo de ensino deve articular o "aprender a filosofia" com o "aprender a filosofar". Ele também demonstra a indissociabilidade entre um e outro, pois só "se aprende a filosofar estudando filosoficamente a filosofia efetivamente existente" (2002, p. 104). Ao aplicar a famosa distinção kantiana sobre ensinar filosofa e ensinar a filosofar aos tipos de conteúdos do ensino, Obiols conclui que o filosofar diz respeito aos conteúdos de ordem atitudinal e procedimental, enquanto que a filosofia se refere aos conteúdos conceituais.

Mario Porta (2014) também defende uma metodologia de estudo e uma didática da filosofia centrada na ideia de problema. Ele argumenta que um dos principais motivos da existência da crença de que a filosofia é de difícil compreensão e até mesmo arbitrária é gerado pela falta de entendimento do problema filosófico proposto. Desse modo, Porta defende que sua compreensão constitui o núcleo essencial tanto do ensino quanto da aprendizagem da disciplina. ${ }^{4}$

4 Embora não seja do escopo deste artigo, vale ressaltar que o vocabulário empregado está em consonância com aquele presente nas principais diretrizes educacionais para o ensino de filosofia. Na BNCC, a filosofia, junto da sociologia, é mencionada como uma área que desempenha a função importante de servir ao "aprofundamento e ampliação da base conceitual e dos modos de construção da argumentação e sistematização do raciocínio, operacionalizados com base em procedimentos analíticos e interpretativos" (2018, p. 472). 
O que os modelos de Gallo, Cerletti, Obiols e Porta (assim como a proposta em nível mais básico de Murcho) possuem em comum é: 1) a centralidade do problema e 2) um aspecto formal que não se compromete especificamente com nenhuma tradição da filosofia. O problema é inevitável em filosofia, e acreditamos que seja ele o elo capaz de envolver o aluno e fazê-lo apropriar-se da discussão à procura de soluções e argumentos que as fundamentam. ${ }^{5}$

Partindo desse posicionamento metodológico, isto é, dessa defesa da abordagem da disciplina ser por meio de problemas, podemos então pensar os aspectos conceituais do ensino: a substância com que preenchemos esse formato.

Em um importante artigo sobre o ensino de filosofia no Brasil, Franklin Leopoldo e Silva (1986) indaga-nos se a história da filosofia deve ser tomada como centro ou referência em uma aula de filosofia. Defendemos que a segunda opção seja privilegiada, pois a história da filosofia, assim como a história das artes e das ciências, deve surgir como fundamento e orientação às questões consideradas em aula. A história da filosofia, assim como os saberes científicos e produção artística são indispensáveis ao ensino, porém, considerando o ensino de filosofia, tais elementos não devem ser o objetivo final do curso, mas sim o combustível das discussões. A partir da história da filosofia, seus autores, tradições, e outras referências, serão ensaiadas respostas aos problemas surgidos na aula. ${ }^{6}$

\section{EXEMPLOS UTILIZADOS EM SALA DE AULA}

Tendo como pano de fundo o que foi discutido, é possível destacar exemplarmente tal abordagem. Exemplos podem ser apresentados em filosofia política. Em sala de aula, antes de tudo, iniciamos com alguns dos principais problemas que envolvem o tema, como: O que é a justiça? O que é a democracia? Qual a melhor forma de governo? Por quê? Ou, ainda, antes de introduzir a teoria contratualista, questionamos: o que é o Estado? Por que ele existe? O que legitima a autoridade política? Por quê?

Outros exemplos podem ser expostos em ética: no que consiste dizer que uma conduta é certa ou errada? Somos livres e responsáveis por nossas ações? O que você faria diante de determinada situação? Por quê?

Saindo do que comumente é denominado de filosofia prática, outras áreas também podem ser facilmente inseridas nessa proposta. Alguns outros exemplos podem ser vistos em antropologia filosófica: O que é o ser humano? Há uma diferença essencial entre o ser humano e os outros animais? Se sim, qual? Por quê? Ou em epistemologia: O que é conhecimento? Qual a origem do conhecimento? É possível conhecer algo? Por quê? ${ }^{7}$

\footnotetext{
5 Esse ponto será melhor desenvolvido e justificado na seção sobre o ensino de filosofia e educação popular.

6 Disso não se segue, é claro, que os problemas serão resolvidos, ou que não surgirão outros novos e até mais complexos. Tratando a história da filosofia, seus sistemas, tradições e teorias, as possibilidades na aula de filosofia são inúmeras. Por isso, não se deve cair no erro de tentar excluí-la do currículo, a fim de realizar aquilo que Obiols denomina de "formalismo pedagógico" (2002, p. 77), que consiste num modelo de ensino puramente baseado no "ensinar a filosofar" e desprovido de quaisquer conteúdos.

7 Ter em vista quais os conteúdos de filosofia que se sobressaem na prova do ENEM são de extrema relevância para, a partir daí, estipular quais problemas abordar em sala de aula. Ou seja, a escolha por problemas não deve ser arbitrária. Estes foram destacados apenas à título de exemplo e de proposta, sendo possível modifica-los conforme o conteúdo e área da filosofia que se está trabalhando.
} 
Conforme pode-se experimentar em sala de aula, uma proposta de discussão baseada naquela que é considerada por muitos como a questão mais fundamental da filosofia, a saber, "o que existe?", provou-se como um problema extremamente envolvente. A pergunta "o que existe?" (na qual também se utiliza seus sinônimos como "o que há?) suscita grandes debates e necessariamente leva a outras questões importantes da ontologia como "todas as coisas existem da mesma forma ou possuem 'existências' diferentes?", e outras. Para qualquer professor(a) de filosofia é extremamente significativo presenciar a turma envolvida numa arguição sobre qual a diferença entre dizer, por exemplo, que uma árvore existe para dizer que um número (ou personagem fictício, instituição social, etc.) existe.

Assim, portanto, antes de se pensar em filósofos(as), conceitos, pensamentos, tradições, o essencial é pensar a própria atitude filosófica, e apropriar-se dela a fim de formar uma nova postura ante as coisas. Tal posicionamento, que pressupõe dar um passo atrás para o questionamento, é o ponto de partida da aula de filosofia.

\section{O ENSINO DE FILOSOFIA A PARTIR DE PROBLEMAS E A EDUCAÇÃO POPULAR}

Como visto, o Alternativa conta com educandos que 1) raramente tiveram um contato próximo com a filosofia, 2) ou esse contato foi superficial, 3) ou nunca tiveram. Em vista disso, concluímos que o ensino a partir de problemas é uma forma didaticamente mais interessante de abordar a filosofia no contexto da educação popular, pois abre mais possibilidades, tanto para o educando que nunca ou pouco teve contato com o conteúdo, quanto para o que já é familiarizado, de entrar na discussão. No momento em que oportunizamos isso ao educando, estamos levando em consideração seus saberes, possibilitando inclusive que o mesmo exponha, através de seus posicionamentos, sua experiência individual enquanto indivíduo, ponto que Paulo Freire $(1986,2011)$ defende veementemente.

É ingênuo acreditar que o papel dos educandos na situação pedagógica se limita a receber a transmissão do conhecimento do objeto que o educador faz (FREIRE, 1986). Tendo isso em vista, tal abordagem também proporciona transformar a aula em diálogo - um diálogo entre educador e aluno, e entre os próprios alunos -, e não apenas em um monólogo por parte do educador. Freire reitera diversas vezes que ensinar exige disponibilidade para o diálogo.

Testemunhar a abertura aos outros, a disponibilidade curiosa à vida, a seus desafios são saberes necessários à prática educativa. Viver a abertura respeitosa aos outros e, de quando em vez, de acordo com o momento, tomar a própria prática de abertura ao outro como objeto da reflexão crítica deveria fazer parte da aventura docente. (2011, p. 90)

Além disso, o ensino a partir de problemas oferece à turma um engajamento real com a atividade da filosofia: a reflexão sistemática, metódica e autônoma sobre certos problemas (PORTA, 2014, p. 25), e não apenas um esforço de cunho histórico - saber o que determinado(a) filósofo(a) disse em um período específico. Instigar o educando a refletir, a falar, argumentar, debater e se engajar faz parte de uma educação emancipatória e libertadora, proposta cuja educação popular é baseada. Devemos 
Thaumazein, Ano IX, v. 13, n. 25, Santa Maria, p. 67-74, 2020.

Estimular a pergunta, a reflexão crítica sobre a própria pergunta, o que se pretende com esta ou com aquela pergunta em lugar da passividade em face das explicações discursivas do professor, espécies de respostas às perguntas que não foram feitas. Isto não significa realmente que devamos reduzir a atividade docente, em nome da defesa da curiosidade necessária a puro vaivém de perguntas e respostas que burocraticamente se esterilizam. A dialogicidade não nega a validade de momentos explicativos, narrativos, em que o professor expõe ou fala do objeto. O fundamental é que professor e alunos saibam que a postura deles, do professor e dos alunos, é dialógica, aberta, curiosa, indagadora e não apassivada, enquanto fala ou enquanto ouve. O que importa é que professor e alunos se assumam epistemologicamente curiosos. (FREIRE, 2011, p. 57-58)

Uma proposta de ensino na educação popular cuja base é a pergunta, a reflexão, a busca por respostas à problemas, enseja, além do mais, a possibilidade do estudo servir como um meio que possibilita e estimula a criticidade do educando para compreender a realidade, a política, o país, o mundo concreto e os seus demais problemas (FREIRE; FAUNDEZ, 2014). Um dos objetivos do projeto Alternativa é também este: estabelecer uma conexão dos conteúdos trabalhados em sala de aula com a realidade na qual o educando está inserido.

Portanto, um dos propósitos que baseiam essa proposta é, em síntese, a defesa de que devemos praticar uma pedagogia engajada e "desafiar o sistema da "educação bancária", a abordagem baseada na noção de que tudo o que os alunos precisam fazer é assumir a informação dada por um professor e ser capazes de memorizá-la e armazená-la" (HOOKS, 2013, p. 26).

\section{CONCLUSÃO}

Ensinar filosofia, como aqui foi defendido, envolve desenvolver habilidades e competências que, por sua vez, servirão como ferramentas à atividade filosófica - que é o coração da aula. Tal atividade é suscitada por sensibilizações e problematizações, que para serem resolvidas, deverão passar por um processo de investigação, conceituação e fundamentação que demanda recorrer à história da filosofia (suas teorias, conceitos, autores, etc) e, consequentemente, envolve a leitura de textos (principalmente filosóficos, mas também literários, jornalísticos) e referência à ciência, contudo, que não deve, como pretendemos ter mostrado, estar restrito a ela.

A escolha por esse método de abordagem da filosofia na educação popular foi pensada, do mesmo modo, tendo em vista o público-alvo com o qual estamos trabalhando, sua realidade social, suas condições, expectativas e, sobretudo, seus saberes. Assim, tanto eu, a educadora ou o educador, quanto todos os alunos e alunas acabamos sendo participantes ativos, e não consumidores passivos, como bem defende Hooks recordando Freire.

\section{REFERÊNCIAS}

ALLGAYER, A. A.; COSTA, A. R. Qual é o perfil do educando do Projeto Alternativa? In: 29a JAI - Jornada

Acadêmica Integrada, 2014, Santa Maria. $29^{\circ}$ Salão de Iniciação Científica, 2014. p. 1-5. 
BRASIL. Ministério da Educação. Base nacional Comum Curricular: 4ª versão. Brasília, DF, 2018.

CERLETTI, Alejandro. 0 ensino de filosofia como problema filosófico. Belo Horizonte: Autêntica Editora, 2009.

FREIRE, Paulo. Pedagogia da autonomia: saberes necessários à prática educativa. São Paulo: Paz e Terra, 2011.

. Educação Popular no Brasil. In: Colóquio Nacional de Educação Popular, 1º, Passo Fundo, RS, 23 a 26 de outubro de 1984. Passo Fundo, 1986, p. 171-194.

FREIRE, Paulo; FAUNDEZ, Antonio. Por uma pedagogia da pergunta. São Paulo: Paz e Terra, 2014.

GALLO, Silvio. Metodologia do ensino de filosofia: uma didática para o ensino médio. Campinas: Papirus, 2012.

HOOKS, bell. Ensinando a transgredir: a educação como prática de liberdade. Trad. Mario Cipolla. Martins Fontes: São Paulo, 2013.

LEOPOLDO E SILVA, Frank. História da filosofia: centro ou referencial? In: NETO, H. N. (Org.) 0 ensino de filosofia no $\mathbf{2}^{\mathbf{0}}$ grau. São Paulo: SOFIA: SEAF, 1986. p. 153-162.

MURCHO, Desidério. A natureza da Filosofia e o seu ensino. Educação (UFSM), Santa Maria, dez. 2011. ISSN 1984-6444. Disponível em: https://periodicos.ufsm.br/reveducacao/article/view/4435.

OBIOLS, Guilherme. Uma introdução ao ensino de filosofia. Ijuí: Editora Unijuí, 2002.

PORTA, Mario Ariel Gonzalez. A filosofia a partir de seus problemas: didática e metodologia do estudo filosófico. $4^{\mathrm{a}}$ ed. São Paulo: Edições Loyola, 2014.

ZAGO, Nadir. Cursos Pré-vestibulares populares: limites e perspectivas. Perspectiva. Florianópolis, v. 26, n. 1, p. 149-174, 2008. 